\title{
In vitro Antifungal Potency of Plant Extracts against Post-Harvest Storage Fungal Pathogens of Zea mays L.
}

\author{
Asha Sinha*, Shakshi Singh, Shrvan Kumar and Shivam Rai \\ Mycology and Plant Pathology, IAS, Banaras Hindu University, \\ Varanasi-221 005, (U.P.), India \\ *Corresponding author
}

\begin{tabular}{|l|}
\hline Ke y w o r d s \\
Seed borne mycoflora, \\
Zea mays, Botanicals, \\
Simpson index of \\
dominance
\end{tabular}

\section{A B S T R A C T}

Keeping in view the immense importance of seed the present investigation was carried out to detect 14 seed borne mycoflora of maize variety Vivek 27 by using Agar plate method and Blotter paper method. Per cent maximum relative density, frequency and abundance values recorded in Aspergillus niger (25.164, 10.638 and 28.652) and (23.538, 9.434 and 27.174) followed by Rhizopus stolonifer (14.309, 10.638 and 16.292) and (13.652, 9.434 and 15.761), Aspergillus flavus (13.322, 10.638 and 15.169) and (13.652, 9.434 and 15.761), Aspergillus fumigatus (8.018, 8.511 and 7.303) and (7.061, 7.547 and 6.522), Curvularia lunata (8.018, 8.511 and 7.303) and (4.708, 9.434 and 5.435), Alternaria alternata $(6.414,10.638$ and 7.303) and (6.120, 9.434 and 7.065) by Agar plate method and Blotter paper method, respectively. Seeds treatment with five plant products, viz. neem, tulsi, onion, ginger and garlic were tested against suppression of seed borne fungi of maize seeds variety Vivek 27 at ratio of 1:1 (w/v). Fungi suppressed after seed treatment with selected botanicals were Rhizopus stolonifer, Mucor globosus, Aspergillus candidus, A. flavus, A. fumigatus, A. niger, Penicillium citrinum, P. expansum, P. notatum, $P$. versicolor, Rhizoctonia solani, Alternaria alternata, Fusarium oxysporum, F. roseum and Curvularia lunata.

\section{Introduction}

Demand for food poses major challenges to humankind due to rising population. For facing these challenges humans used enormous amount of chemically synthesize fungicides because of their enormous use, easiness and extreme effectiveness to control plant diseases. Due to their harmful effects on human being as well as soil health, nowadays focus is shifting in the direction of biological methods to manage plant diseases as they have no adverse consequence on humans as well as environment. Maize (Zea mays L.) is the very resourceful crop with wider adaptability in varied agro-ecologies. United States of America, Argentina, China, Brazil, Mexico and India are major maize growing country in world. Maize is the $3^{\text {rd }}$ most significant food crops in India after rice and wheat (the average productions in India are $2.43 \mathrm{t} \mathrm{ha}^{-1}$ ). It is cultivated for diverse purposes in different parts of the country throughout the year as grain, fodder, green cobs, sweet corn, baby corn, popcorn and industrial purposes etc. The 
major maize growing states are Andhra Pradesh (20.9 \%), Karnataka (16.5\%), Rajasthan (9.9\%), Maharashtra (9.1\%), Bihar (8.9\%), Uttar Pradesh (6.1 \%), Madhya Pradesh (5.7\%) and Himachal Pradesh (4.4 $\%$ ), which contributes more than $80 \%$ of the total maize production (Barupal and Sharma, 2015).

It has got immense potential and hence called as 'Miracle crop' and also called as 'Queen of cereals'. Seeds are a gift of nature, of past generation and diverse culture. It is our inherent duty to protect them and to pass them on to future generation. Deterioration of stored seeds and grains by fungus is a major problem in India. During storage, grains are colonized by various fungal species undergo quantitative and qualitative losses due to mycotoxin production (Wahegaonkar and Shirurkar, 2013 and Ganesh and Patel, 2014).

There are restrictions on use of fungicides and pesticides (Pal and Gardener, 2006). So, it is very essential to develop control measures as alternative to chemicals (Raghavender et al., 2009 and Singh et al., 2014). Plant metabolites and plant based antifungal formulation appear to be one of the better alternatives as they are known to have minimal environmental impact and danger to consumers in comparison to the synthetic pesticides (Verma and Dubey, 1999). Some traditionally useful plants have been shown to exhibit fungi-toxic property (Awuah, 1996).

Plant extracts as control measures are cost effective and non-toxic methods. Plant based antifungal formulation are now being used (Omer, 2010). In present investigation, to detect seed borne mycoflora of maize variety Vivek 27 by using Agar plate method and Blotter paper method, and antifungal activity of various plant extracts on growth of seed borne fungi had been carried out.

Materials and Methods

\section{Collection of seed samples}

The seed samples were collected from local market and preserved in cloth bags at room temperature during the studies as described by Neergaard (1973).

\section{Determination of seed Mycoflora}

\section{Agar plate method (Muskett, 1948)}

Sterilized Potato Dextrose Agar (PDA) medium was poured aseptically into sterilized Petri-dishes was allowed to cool and settle down. Ten seeds were placed in each Petriplate containing solidify PDA. There were two replications each having 50 seeds. All the Petri-plates containing seeds were incubated at $25 \pm 1^{\circ} \mathrm{C}$ for a week under 12 hours alternating cycles of light and darkness. Fungi growing on seeds were isolated and identified under microscope.

\section{Standard blotter technique (de Tempe, 1953)}

The blotting paper was sterilized and then three pieces of sterilized blotting papers in folds moistened with sterilized distilled water were placed in each sterilized Petri dish of 9 $\mathrm{cm}$ diameter. Ten seeds were placed equal distance on blotter in each Petri dish.There were two replications each having 50 seeds. The Petri-plates were incubated at $25 \pm 1{ }^{\circ} \mathrm{C}$ under 12 hours alternating cycle of light and darkness. Plated seeds were observed from time to time for the presence and growth of fungal species on the seeds.

The seed mycoflora were identified with the help of literature (Thom and Raper, 1945; Raper and Thom, 1949; Barnett, 1962; Klich, 2002; Leslie and Summerell, 2008; Visagie et al., 2014; URL 1 and 2). Based on the individuals fungi recorded in the distinct seed 
samples were analysed for density, frequency, abundance, relative density, relative frequency, relative abundance, importance value index, Simpson index of Dominance, Shannon- Weaver Index of Diversity and evenness. The importance value index of seed sample was determined as the sum of relative frequency, relative densityand relative dominance (Curtis and McIntosh, 1950).

Density is calculated by the equation:

Density $=\frac{\text { Total number of individuals of a species in all Petri plate }}{\text { Total number of Petri plate studied }}$

Frequency $(\%)$ is calculated by the equation:

Frequency $(\%)=$

Number of Petri plate in which the species occurred X 100

Total number of Petri plate studied

\section{Abundance}

It is the study of the number of individuals of different species in the community per unit area. It is represented by the equation:

Abundance $=$

Total number of individuals of a species in all Petri plate Total number of individuals of a species in all Petri plate

Relative density, relative frequency and relative abundance were calculated as:

Relative density $=\frac{\text { Number of individuals of a species X } 100}{\text { Number of Petri plate studied }}$

Relative frequency $=\frac{\text { Number of occurrence of the species } \mathrm{X} 100}{\text { Number of occurrence of all the species }}$

Relative abundance $=\frac{\text { Total Petri plate of the species } \times 100}{\text { Total Petri plate of all the species }}$

Importance Value Index (IVI)
It was calculated by equation (Burlakoti and Karmacharya, 2004):

IVI $=$ Relative frequency + Relative density + Relative dominance

The maximum importance value for any one genus is $300(100+100+100)$. It is useful, as it provides an overall picture of the density, frequency and cover of a genus in relation to community.

\section{Simpson's Dominance Index (D)}

The Simpson's index (D) is calculated using the following equation (Simpson, 1949):

$\mathrm{D}=\frac{\sum_{i=1}^{s} n_{i}\left(n_{i}-1\right)}{n(n-1)}$

Where 'ni' is the proportion of individuals of the with species in the community. Simpson's index gives relatively little weight to the rare species and more weight to the common species. It weighs towards the abundance of the most common species. It ranges in value from 0 (low diversity) to a maximum of (1$1 / \mathrm{s}$ ), where $\mathrm{s}$ is the number of species. In nature the value of $\mathrm{d}$ ranges between 0 and 1 . With this, index 0 represents infinite diversity and 1 , no diversity. The bigger the (D) value, the smaller the diversity.

\section{Shannon-Wiener Index (H)}

This is a widely used method of calculating biotic diversity in aquatic and terrestrial ecosystems and is expressed as SWI (Shannon and Weaver, 1963):

$$
\mathrm{H}^{\prime}=\sum_{i=1}^{s} \frac{n_{i}}{n} \ln \frac{n_{i}}{n}
$$

Where, $\mathrm{H}=$ index of species diversity $\mathrm{s}=$ 
number of species ni= proportion of total sample belonging to the ith species.

\section{Evenness index (E)}

This is relative distribution of individuals among taxonomic groups within a community and is expressed (Pielou, 1966) as:

$\mathrm{E}=\mathrm{H}^{\prime} / \log \mathrm{S}$

Where, $\mathrm{H}^{\prime}=$ Shannon -Wiener diversity index, and $\log S=$ Natural $\log$ of the total number of species ( $\mathrm{S}$ defined as Species Richness) recorded.

\section{Screening of plant extracts}

Abundantly use of synthetic pesticides and commercial antibiotic for human and crop protection is harmful to environment, ecosystem as well as human health. This study was carried out to know the efficacy of different plant extracts on seed-borne fungi of maize. Evaluation of five plants extracts viz., neem, tulsi, onion, ginger and garlic were tested against the seed borne fungi of maize in Table 1. Botanicals were collected from the local area and market. Plant extract prepared by macerating leaves /bulb/rhizomes /cloves in ratios weight / volume (1:1) in distilled sterilize water or methanol and termed as standard extract (SE).

\section{Results and Discussion}

Estimation of seed borne fungi by Agar plate method

A total of 12 fungal species were isolated from maize variety Vivek 27 viz., Rhizopus stolonifer, Mucor globosus, Aspergillus flavus, Aspergillus fumigatus, Aspergillus niger, Penicillium notatum, Penicillium versicolor, Alternaria alternata, Curvularia lunata, Fusarium moniliforme, Microdochium fisheri and Rhizoctonia solani by Agar plate method (Table 2). Per cent maximum relative density, frequency and abundance values recorded in Aspergillus niger (25.164, 10.638 and 28.652) followed by Rhizopus stolonifer (14.309, 10.638 and 16.292), Aspergillus flavus (13.322, 10.638 and 15.169), Aspergillus fumigatus (8.018, 8.511 and 7.303), Curvularia lunata (8.018, 8.511 and 7.303), Alternaria alternata $(6.414,10.638$ and 7.303), Microdochium fisheri (6.168, 4.255 and 2.809), Mucor globosus (5.756, 6.383 and 3.933), Fusarium moniliforme (4.934, 10.638 and 5.618) and Penicillium notatum (2.960, 10.638 and 3.371).

Whereas, lowest per cent of relative density, frequency and abundance were recorded in Penicillium versicolor $(2.467,6.383$ and $1.685)$ and Rhizoctonia solani $(2.467,2.128$ and 0.562), respectively. Myco-diversity showed Simpson index of dominance (D) values range from 0.0462 to 0.0003 .

The Shannon-Weiner diversity index $(\mathrm{H})$ value ranges were from 0.330 to 0.070 . Pielou's evenness index (E) of myco-flora showed value ranges from 0.133 to 0.028 .

\section{Estimation of seed borne fungi by Blotter paper method}

A total of 14 fungal species were isolated from maize variety Vivek 27 viz., Rhizopus stolonifer, Mucor globosus, Aspergillus flavus, Aspergillus fumigatus, Aspergillus niger, Penicillium expansum, Penicillium notatum, Penicillium versicolor, Alternaria alternata, Curvularia lunata, Fusarium moniliforme, Fusarium oxysporum, Microdochium fisheri and Rhizoctonia solani by Blotter paper method (Table 3). In Blotter paper method, per cent maximum relative density, frequency and abundance values recorded in Aspergillus niger (23.538, 9.434 and 27.174) followed by Rhizopus stolonifer (13.652, 9.434 and 
15.761), Aspergillus flavus (13.652, 9.434 and 15.761), Fusarium moniliforme (7.650, 7.547 and 7.065), Aspergillus fumigatus (7.061, 7.547 and 6.522), Alternaria alternata (6.120, 9.434 and 7.065), Mucor globosus (5.885, 3.774 and 2.717), Curvularia lunata (4.708, 9.434 and 5.435), Penicillium expansum (4.708, 5.660 and 3.261), Fusarium oxysporum (3.138, 5.660 and 2.174) and Penicillium notatum (2.825, 9.434 and 3.261$)$, respectively.

However, minimum per cent of relative density, frequency and abundance were recorded in Penicillium versicolor (2.354, 5.660 and 1.630) at par with Microdochium fisheri (2.354, 3.774 and 1.087) and Rhizoctonia solani (2.354, 3.774 and 1.087), respectively by Blotter paper method on maize variety Vivek 27. Diversity of myco-flora in this study calculated using the ShannonWeiner diversity index $\left(\mathrm{H}^{\prime}\right)$ value ranges were from 0.322 to 0.090 . Myco-diversity showed Simpson index of dominance (D) values range from 0.0402 to 0.0006 . Pielou's evenness index (E) of myco-flora showed value ranges from 0.122 to 0.034 .
Occurrence of mycoflora on maize seeds after treatment with plant products by Agar plate method

Seeds treatment with five plant products, viz. neem, tulsi, onion ginger and garlic were tested against suppression of seed borne fungi of maize seeds variety Vivek 27 by Agar plate method at ratio of $1: 1(\mathrm{w} / \mathrm{v})$ are presented in Table 4. Fungi suppressed after seed treatment with neem leaf extract were Mucor globosus, Aspoergillus flavus, Penicillium notatum, Penicillium versicolor and Rhizoctonia solani. Fungi suppressed after seed treatment with tulsi leaf extract viz., Penicillium notatum and Penicillium versicolor. However, Mucor globosus, Penicillium versicolor and Rhizoctonia solani were suppressed after seed treatment with onion bulb extract. Ginger rhizomes extract treated maize seeds suppressed Rhizopus stolonifer, Aspergillus flavus, Aspergillus niger, Penicillium versicolor and Rhizoctonia solani. Garlic cloves extract treated seeds suppressed the Rhizopus stolonifer, Mucor globosus, Aspergillus fumigatus, Aspergillus niger, Penicillium notatum, Alternaria alternata, Curvularia lunata and Rhizoctonia solani.

\begin{tabular}{|l|c|c|c|c|c|}
\multicolumn{5}{|c|}{ Table.1 The particulars of botanicals used for seed treatment is given below } \\
\hline S. No. & $\begin{array}{c}\text { Common } \\
\text { name }\end{array}$ & Botanical Name & Family & $\begin{array}{c}\text { Plant parts } \\
\text { used }\end{array}$ & $\begin{array}{c}\text { Dilutions } \\
\text { (w/v) }\end{array}$ \\
\hline $\mathbf{1 .}$ & Neem & Azadirachta indica A.Juss & Meliaceae & Leaves & $1: 1$ \\
\hline $\mathbf{2 .}$ & Tulsi & Ocimum sanctum L. & Lamiaceae & Leaves & $1: 1$ \\
\hline $\mathbf{3 .}$ & Onion & Allium cepa L. & Amaryllidaceae & Bulbs & $1: 1$ \\
\hline $\mathbf{4 .}$ & Ginger & Zingiber officinale Roscoe & Zingiberaceae & Rhizomes & $1: 1$ \\
\hline $\mathbf{5 .}$ & Garlic & Allium sativum L. & Amaryllidaceae & Cloves & $1: 1$ \\
\hline
\end{tabular}


Table.2 Estimation of seed borne fungi of maize variety Vivek 27 by Agar plate method

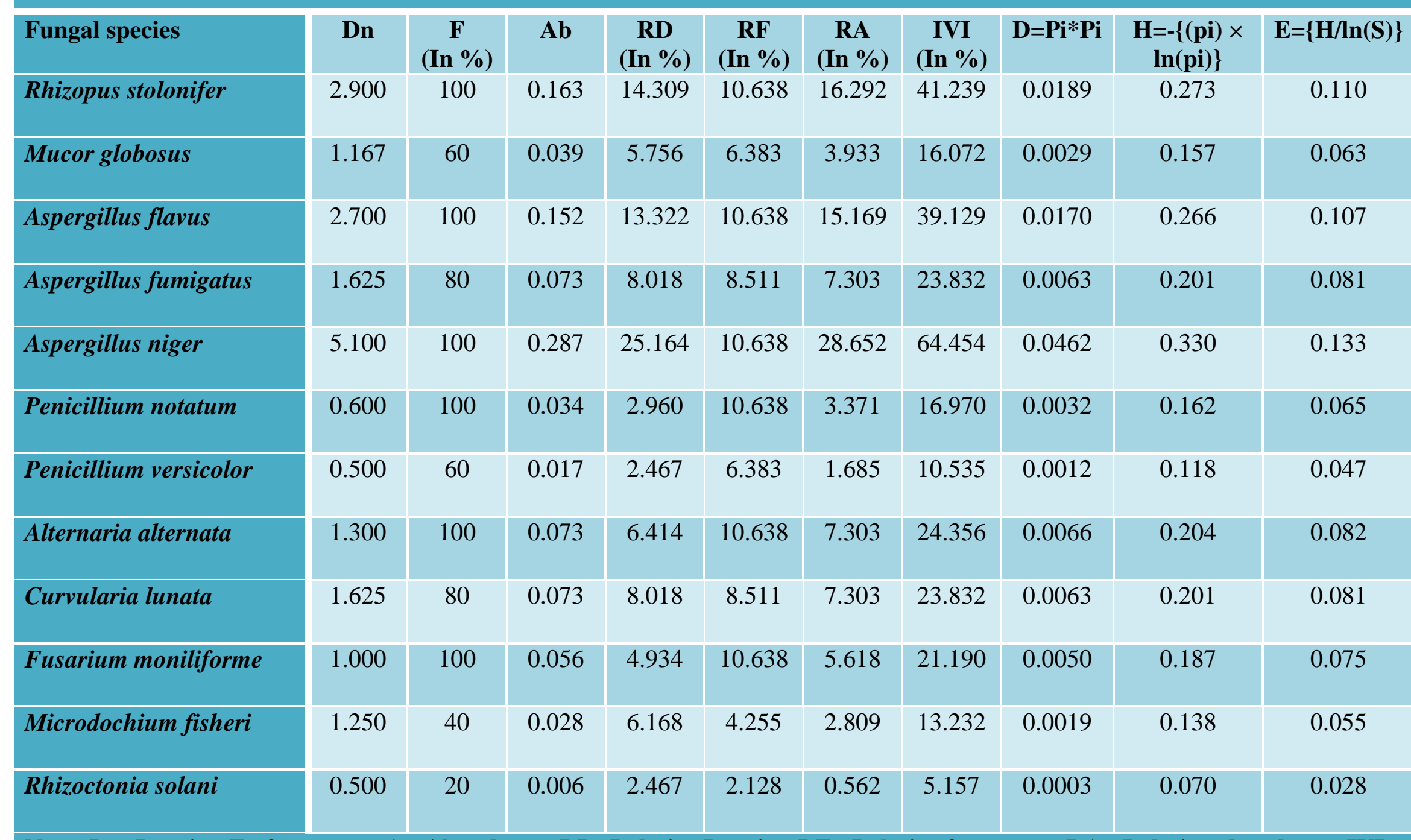

Note: Dn=Density, F= frequency, A= Abundance, RD=Relative Density, RF= Relative frequency, RA= Relative abundance, IVI=

Importance value index, $\mathrm{D}=$ Simpson index of Dominance, $\mathrm{H}=$ Shannon- Weaver Index of Diversity, $\mathrm{E}=\mathrm{Evenness}$ 
Table.3 Estimation of seed borne fungi of maize variety Vivek 27 by Blotter paper method

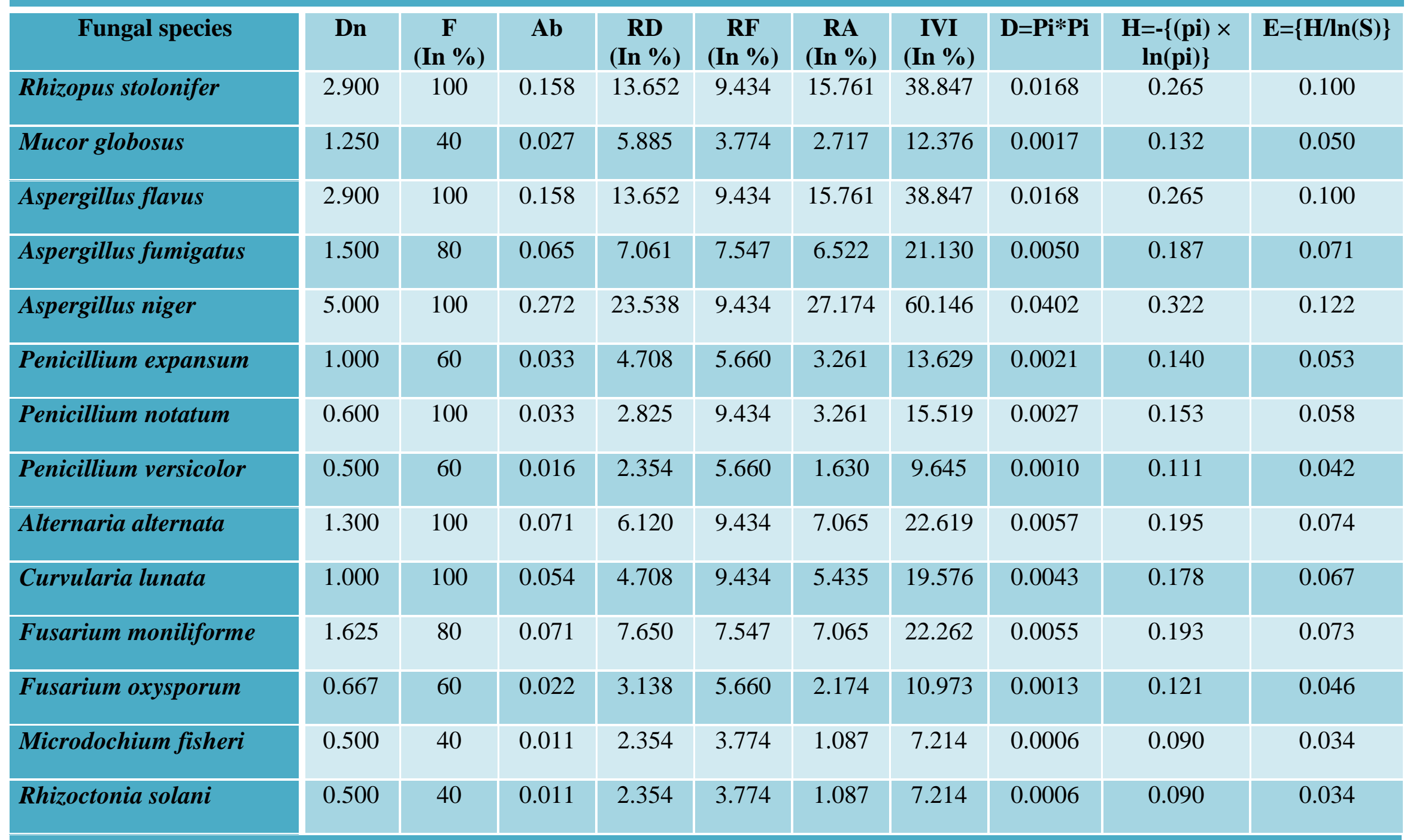

Note: Dn=Density, F= frequency, A= Abundance, RD=Relative Density, RF= Relative frequency, RA= Relative abundance, IVI= Importance value index, $\mathrm{D}=$ Simpson index of Dominance, $\mathrm{H}=$ Shannon- Weaver Index of Diversity, $\mathrm{E}=\mathrm{Evenness}$ 
Table.4 Occurrence of mycoflora on maize seeds after treatment with methanolic plant products by Agar plate method

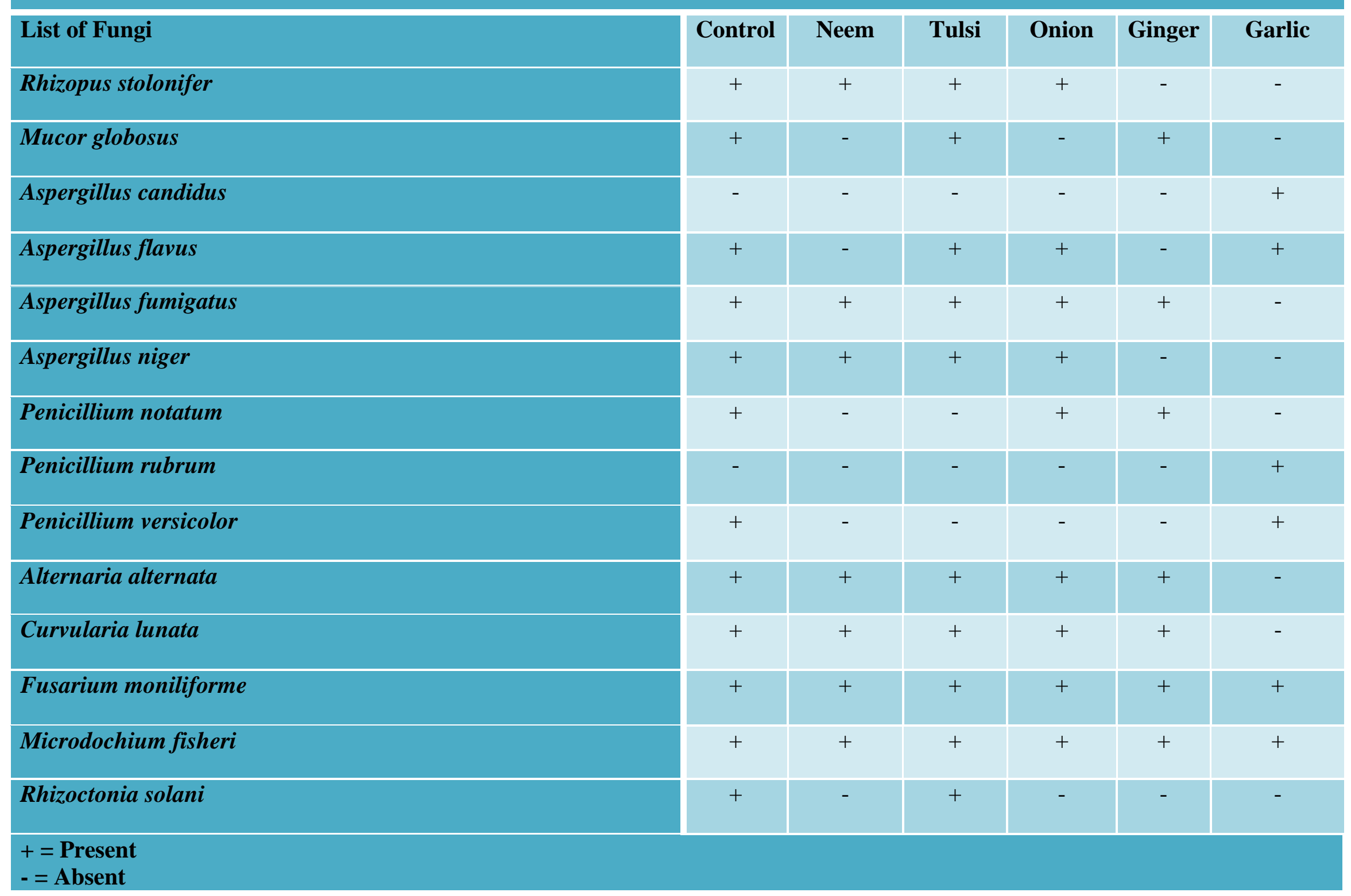


Table.5 Occurrence of mycoflora on maize seeds after treatment with methanolic plant products by Blotter paper method

\begin{tabular}{|c|c|c|c|c|c|c|}
\hline List of Fungi & Control & Neem & Tulsi & Onion & $\begin{array}{l}\text { Gin } \\
\text { ger }\end{array}$ & Garlic \\
\hline Rhizopus stolonifer & + & + & + & + & - & - \\
\hline Aspergillus candidus & - & + & - & + & - & + \\
\hline Aspergillus flavus & + & - & + & + & + & + \\
\hline Aspergillus niger & + & + & + & + & - & - \\
\hline Penicillium citrinum & - & - & - & - & + & + \\
\hline Penicillium expansum & + & + & + & - & + & - \\
\hline Penicillium notatum & + & - & - & + & + & + \\
\hline Curvularia lunata & + & + & + & + & + & - \\
\hline Fusarium moniliforme & + & + & + & + & + & + \\
\hline Fusarium oxysporum & + & - & + & + & - & + \\
\hline Fusarium roseum & - & + & + & - & - & - \\
\hline Microdochium fisheri & + & + & + & + & + & + \\
\hline Rhizoctonia solani & + & - & + & - & - & - \\
\hline $\begin{array}{l}+=\text { Present } \\
\text { - = Absent }\end{array}$ & & & & & & \\
\hline
\end{tabular}


Occurence of mycoflora on maize seeds after treatment with plant products by Blotter paper method

Treatment of seeds with five plant products, viz. neem, tulsi, onion ginger and garlic were tested against suppression of seed borne fungi of maize seeds variety Vivek 27 by Blotter paper method at ratio of $1: 1(\mathrm{w} / \mathrm{v})$ are presented in Table 5. By using Blotter paper method, neem leaf extract treated seeds suppressed Mucor globosus, Aspergillus flavus, Penicillium notatum, Penicillium versicolor, Fusarium oxysporum and Rhizoctonia solani. The occurrence of two new fungal species were observed after seeds treatment with neem leaf extract by using Blotter paper method viz., Aspergillus candidus and Fusarium roseum, which were absence in control. The fungal species suppressed after treatment with tulsi leaf extract were Penicillium notatum and Penicillium versicolor. It was observed that the Fusarium roseum was observed after seed treatment with tulsi leaf extract, which was absent in control. The fungal species which suppressed after treatment with onion bulb extract were Mucor globosus, Penicillium expansum, Penicillium versicolor and Rhizoctonia solani. The fungal species suppressed after the treatment with ginger rhizomes extracts were Rhizopus stolonifer, Aspergillus niger, Penicillium versicolor, Fusarium oxysporum, and Rhizoctonia solani. Both, Aspergillus candidus and Penicillium citrinum were found after seed treatment with garlic cloves extracts.

Maize seeds were mostly infected by toxin producing fungi such as Fusarium spp., Aspergillus spp. and Penicillium spp. (Mostafa and Kazem, 2011). Frequency occurrence of Aspergillus niger and A. flavus was very high in maize (Shirurkar and Wahegaonkar, 2013). The most prevalent genus as external seed -borne mycoflora was
Aspergillus spp. (Dawood et al., 2015). The fungi from Alternaria, Fusarium and Penicillium spp. were most frequently isolated from maize grain. These three genera are potential mycotoxin producers (Gulbis et al., 2016). Among the storage fungal pathogens Aspergillus, Fusarium and Penicillium are the most dominant species attacking maize seed. The highest frequency of Aspergillus spp. (40.4\%) at farmer preserved seed with surface disinfected kernels on agar plate were recorded (Tsedaley and Adugna, 2016). Garlic leaves extract inhibited the growth of 5 fungal species viz. Aspergillus flavus, A niger, A. oryzae, Fusarium verticillioides and Penicillium sp. while garlic bulb extract inhibited the growth of 3 fungal species viz. Aspergillus niger, A. oryzae and Penicillium sp. Neem leaves extract showed inhibitory activity against Aspergillus flavus, A. niger, A. terreus, A. oryzae and Penicillium sp. (Wahegaonkar and Shirurkar, 2013). Garlic extract and neem extract significantly reduce the seed borne fungi of maize (Harris et al., 2001; Irkin and Korukluoglu, 2007; Mossini et al., 2009 and Debnath et al., 2012).

This study indicated that more efficient ecofriendly treatments like botanicals with lesser use of fungicides may provide a better management of the disease.

The infection of seeds due to seed borne fungi and also their toxins are considerable as a threat of human health and animals and by detection of these fungi practical solution to reduce their toxins and hazards. The fungi viz., Rhizopus stolonifer, Aspergillus flavus, A. niger, A. fumigates, Curvularia lunata and Alternaria alternata were most frequently isolated from maize grain in this study. Dry grains to $15 \%$ moisture are very important and monitor grain on regular basis during storage to insure that moisture and temperature are maintained at correct levels. 


\section{Acknowledgment}

Research was funded by Uttar Pradesh Council of Science and Technology for "Development of Eco-friendly formulation of phyto-extracts against seed borne pathogens of Zea mays L".

\section{References}

Awuah, R.T. 1996. Possible utilization of plant products in grain storage. Proceeding of the Workshops on Mycotoxins in Food in Africa, Nov. 610, International Institute of Tropical Agriculture, Benin 32.

Barnett, H.L. 1962. Illustrated genera of imperfect fungi. Burgess Publishing Company, USA.

Barupal, T. and Sharma, K. 2015. Plant extract a novel for Agriculture. Research Journal of Pharmaceutical, Biological and Chemical. 6(2): 934956.

Burlakoti, C. and Karmacharya, S.B. 2004. Quantitative analysis of macrophytes of Beeshazar Tal, Chitwan. Nepal Him. J. Sci. 2(3):37-41.

Curtis, J.T. and McIntosh, R.P. 1950. The interrelations of certain analytic and synthetic phytosociological characters. Ecology. 31:434-455.

Dawood, E.S., Modhi, K. and Elshamry. 2015. Mycoflora of maize (Zea mays) at different locations in Hail Are-Saudi Arabia. International Journal of Scientific \& Technology Research. 4(06):227-230.

De Tempe, J. 1953. The blotter method of seed health testing. Proc. Int. Seed Test. Association. 21: 133-151.

Debnath, M., Sultana, A. and Rashid, A.Q.M.B. 2012. Effect of seed-borne fungi on the germinating seeds and their bio-control in maize. J. Environ. Sci. \& Natural Resources. 5(1):117 - 120.
Ganesh, K. and Patel, S. T. 2014. Frequency and assessment of fungi at different grain formation stages and discolored seeds of sorghum (Sorghum bicolor L. Moench). The Bioscan. 9(1): 243-246.

Gulbis, K., Bankina, B., Bimšteina, G., Neusa-Luca, I., Roga, A. and Fridmanis, D. 2016. Fungal diversity of maize (Zea mays L.) grains. Rural Sustainability Research. 35(330): 2-6.

Harris, J.C., Cottrell, S.L., Plummer, S. and Lloyd, D. 2001. Antimicrobial properties of Allium sativum. J. Appl. Microbiol. Biotechnol.57: 282-286.

Irkin, R. and Korukluoglu, M. 2007. Control of Aspergillus niger with garlic, onion and leek extracts. Afr. J. Biotechnol.6:384-387.

Klich, M.A. 2002. Identification of common Aspergillus species. Centraalbureau voor Schimmelcultures, Utrecht.

Leslie, J.F. and Summerell, B.A. 2008. The Fusarium Laboratory Manual. John Wiley \& Sons 388.

Mossini, S.A. G., Carla, C. and Kemmelmeier, C. 2009. Effect of neem leaf extract and Neem oil on Penicillium growth, sporulation, morphology and ochratoxin A production. Toxins. 1: 313.

Mostafa, A. T. and Kazem, S.S. 2011. Fungi associated with harvested corn grains of Golestan province in Iran. Annals of Biological Research. 2(5):681-688.

Muskett, A.E. 1948. Technique for the examination of seed for the presence of seed borne fungi. Trans. Br. Mycol. Soc. 30:74-83.

Neergaard, P. 1973. Detection of seed born pathogen by culture tests. Seed science and technology. 1: 217-254.

Omer, A.M. 2010. Life Sci. 7.

Pal, K. K. and Gardener, B.M. 2006. Biological Control of Plant Pathogens. The Plant Health Instructor doi: 10.1094/PHI-A-2006-1117-02. 
Pielou, E.C. 1966.An introduction to mathematical Ecology. John Wiley and Sons, New York

Raghavender, C.R., Reddy, K.R. N. and Reddy, B.N. 2009. Fungi as potential biocontrol agents of phytopathogens. In: A. Shahid (Ed.), Plant disease management: For sustainable agriculture. Tri Nagar, Delhi: Daya Publishing House.

Raper, K.B. and Thom, C. 1949.A manual of the penicillia. The Williams \& Wilkins Company, Baltimore. 1-875. doi: http://dx.doi.org/10.5962/bhl.title.4993

Shannon, C.E. and Weaver, W. 1963.The Mathematical Theory of Communication. University of Illinois Press, Urbana, Illinois.

Shirurkar D. and Wahegaonkar, N.K. 2013. Incidence of seed borne mycoflora on maize and its effect on seed germination. International Journal of Current Research. 5(12):4151-4155.

Simpson, E.H. 1949. Measurement of diversity. Nature.163: 688.

Singh, S., Sinha, A., Kumar, S. and Yadav S. M. 2014. Determination of seed germination percent and effect of Trichoderma harzianum Rafai on fresh and stored seed by different methods. The Ecoscan. VI: 181-185.

Thom, C. and Raper, K.B. 1945. A manual of Aspergilli. The Williams \& Wilkins Company, Baltimore. doi: http://dx. doi.org/10.5962/bhl.title.5694.

Tsedaley, B. and Adugna, G. 2016. Detection of fungi infecting maize (Zea mays L.) seeds in different storages around Jimma, Southwestern Ethiopia. J. Plant Pathol. Microbiol 7(3):38-44. doi:10.4172/2157-7471.1000338

URL 1: www.mycobank.org.

URL 2: www.indexfungorum.org.

Verma, J. and Dubey, N.K. 1999. Prospective of botanical and microbial products as pesticides of tomorrow. Current Science. 76: 172-179.

Visagie, C.M., Houbraken, J. and Frisvad, J.C. 2014.Studies in Mycology. 78: 343-371. doi: 10.1016/j.simyco.2014. 09.001 .

Wahegaonkar Nilima, K. and Shirurkar Deepavali, D. 2013. Antifungal activity of selected plant extracts against important seed borne fungi of maize. International Journal of Pharma and Bio Sciences. 4(3): (B) 163 - 170.

\section{How to cite this article:}

Asha Sinha, Shakshi Singh, Shrvan Kumar and Shivam Rai. 2018. In vitro Antifungal Potency of Plant Extracts against Post-Harvest Storage Fungal Pathogens of Zea mays L. Int.J.Curr.Microbiol.App.Sci. 7(04): 1236-1247. doi: https://doi.org/10.20546/ijcmas.2018.704.138 